\title{
Comparative Evaluation of Three Nickel-Titanium Instrumentation Systems in Human Teeth Using Computed Tomography
}

\author{
Fatih. Çakııı, ${ }^{1}$ Aziz Şahin Erdoğan ${ }^{2}$ \\ ${ }^{1}$ Department of Endodontics, Faculty of Dentistry, Ordu University, Ordu, Turkey \\ ${ }^{2}$ Department of Endodontics, Faculty of Dentistry, Atatürk University, Erzurum, Turkey \\ Received: 17 April 2020, Accepted: 25 April 2020, Published online: 30 April 2020 \\ (C) Ordu University Institute of Health Sciences, Turkey, 2020
}

\begin{abstract}
Objectives: Root canal cleaning and shaping during root canal treatment have been one of the important stages in achieving success The objective of this study was to investigate area and volume changing occurring during shaping of the root canals with three different nickel titanium instrument systems (Race, Hero shaper, Protaper).

Method: In this study, 91 upper first molar teeth were used. Teeth divided randomly into 3 groups. Mesio buccal root of first upper molar teeth were shaped with Race, Hero shaper, and Protaper. The CT images were taken before and after shaping. The taken CT images were transferred to mimics software and 3D models were obtained. On these 3D models, area and volume changes were calculated. Data were subjected to one way Anova. Significance level was set at $\mathrm{P}=0.05$

Results: No significant difference was found between the volumes calculated on images in terms of the effectiveness of the instruments $(\mathrm{P}=0.47)$. No significant difference was found between the areas calculated on images in terms of the effectiveness of the instruments $(\mathrm{P}=0.71)$.

Conclusion: Within the limits of this study, all rotary instrument systems showed similar effects in terms of area and volume changes of the root canals at the end of the shaping process.
\end{abstract}

Key words: Hero shaper, Protaper, Race, Root Canal Area, Root Canal Volume,

Suggested Citation: Cakici F, Erdogan AS. Comparative Evaluation of Three Nickel-Titanium Instrumentation Systems in Human Teeth Using Computed TomographyMiddle Black Sea Journal of Health Science, 2020; 6(1):123-128

\section{Address for correspondence/reprints:}

Fatih Çakıcı

Telephone number: +90 (553) 9791598

ORCID-ID 0000000281472661

E-mail: dt_fatihcakici@hotmail.com

DOI: $10.19127 / \mathrm{mbsjohs.} 721925$

\section{Introduction}

Root canal cleaning and shaping during root canal treatment have been one of the important stages in achieving success (Haapasalo et al. 2005; Paqué et al. 2009). Various methods and instruments have been developed for biomechanical removal of the microorganisms, organic and inorganic tissue debris in the root canals and hermetic obturation of the canals.

Hero shaper was manufactured by Micro-mega (Besançon, France) company. It consists of 6 instruments with three different diameters. It has 4$6 \%$ taper and cutting angle, triple helix horizontal 
section and a non-active tip providing tracking the canal. The curve of root canal is the key factor in the selection of consecutive instruments. Easy root canals curve was defined as the roots with a curve lower than 100 , moderate root canals as those with a curve between 100-250 degrees and difficult root canals as the narrow canals with a curve higher than 250 . Instruments and the techniques vary corresponding to degree of canal curve.

Protaper was manufactured by Dentsply maillefer (Ballaigues, Switzerland) company. Three types consist of total 6 instruments (SX, S1, S2, F1, F2, and F3). It has a convex triangle section, varying spiral angle and knife interval, and non-cutting guide tip. The system involves instruments with varying taper angles including auxiliary instrument (SX), shaping instruments (S1, S2) and finishing instruments (F1, F2, F3).

RACE (Reamer with Alternating Cutting Edges) is an instrument manufactured by FKG dentaire (Lachaux de fonds, Switzerland). It has a non-cutting tip design in order to provide easy tool control. Owing to its alternative grooves, working time has decreased without a need for a high torque. Since surface shaping is performed with electrochemical polishing, it has a good resistance against metal fatigue and bending. It has eight breakable memory disks showing metal fatigue. It consists of the instruments with different taper angles.

Studies have shown that instrument designs cause area and volume changes during shaping of the root canals (Ozgur Uyanik et al. 2006; Mahran and AboElFotouh 2008; Ikram et al. 2009). The objective of this study was to investigate area and volume changing occurring during shaping of the root canals with three different nickel titanium instrument systems. The null hypothesis was that there would be no difference among three different nickel titanium instrument systems in terms of the changed area and volume of root canals.

\section{Methods}

This experimental study is taken from thesis "Comparative Evaluation of Three Nickel-Titanium Instrumentation Systems in Human Teeth Using Computed Tomography" done in 2010 at Atatürk University. This study was approved by the Ethics Committee of graduate school of health sciences of Atatürk University, Erzurum, Turkey, (2010).

In this study, 91 upper first molar teeth were extracted due to periodontal and prosthetic reasons. Sample size calculated based on previous studies. The teeth were kept in $10 \%$ formalin solution immediately after the extraction. The teeth were then kept in distilled water. At first, the teeth were kept in 5\% $\mathrm{NaOCl}$ for 24 hours. Inclusion criteria were completion of root development, reaching of No $10 \mathrm{~K}$ file (Mani Inc., Tochigi-ken, Japan) to apical, and teeth with a curve > 250 according to Schneider 1971. Debris in the root surface was cleaned with a curette. After caries and fillings in the crown were cleaned, the occlusal surface of the tooth was smoothed to fix the reference point. Access cavities were prepared using diamond fissure bur (Mani Inc., Tochigi-ken, Japan). Distal and palatinal roots were then cut with a carbon saw and removed. Pulp debris in the root canal was then removed as much as possible utilizing a barbed broaches file. Working length was recorded as $0.5 \mathrm{~mm}$ shorter from the point where $\# 10 \mathrm{~K}$ file was seen in the apical foramen. Preparation was not performed in the second canals. Root apex was covered with pink wax in order to prevent leakage of acrylic into root canals during embedding into acrylic blocks. The samples were embedded into the blocks prepared from orthodontic acryl as the crowns remaining outside.

\section{Computed Tomography (CT) Imaging Before Preparation}

Sample images were acquired using a computed tomography device (Aquillon; Toshiba Medical Systems, Tokyo, Japan) in Ataturk University Medical Faculty Research Hospital department of radiology. Images of the samples inserted to the tomography device were taken in DICOM format under the conditions of $16 \times 0.5 \mathrm{~mm}$ collimation, 0.5 $\mathrm{mm}$ thickness $120 \mathrm{kV}$ and $300 \mathrm{mAs}$. The recorded images and CT data were transferred to the Mimics software of Materialise (Leuven, Belgium) in order to calculate area and volumes of the root canals.

\section{Preparation Process}

Teeth with determined working length and root canal curves were randomly divided into three groups.

Group 1: Shaping of the root canals with RACE

Sequence of the instruments was determined according to manufacturer recommendations. Accordingly; \#10/40 and \#08/35 instruments were used until encountering a resistance in the coronal part of the root. \#02/15 instrument was then used along the working length. Widening in the working length was completed with \# 02/20 and \# 02/25 instruments.

Each instrument was used with Xsmart Dentsply maillefer (Ballaigues, Switzerland) electrical motor at 600 revolutions per minute and $2 \mathrm{~N}$ torque. After the 
use of each instrument, root canals were irrigated with $2 \mathrm{~mL} \mathrm{5 \%} \mathrm{NaOCl}$ irrigation solution. During root canal shaping, 4 leaflets in files were ruptured due to the difficulty of the curved anatomy. The file was not used longer when the leaflets in the disk depleted.

\section{Group 2: Shaping of the root canals with hero} shaper.

In line with the instrument order recommended by the manufacturer in the teeth with difficult canals and a curve $\geq 25 \mathrm{o}$, preparation was made by tracking the yellow line on the "Hero Shaper Box". The shaping was started with \#06/20 instrument. Coronal part or middle $2 / 3$ part of the root canal was shaped with \#06/20 instrument via passive progression technique. Shaping was performed along the working length with \#04/20, \#04/25 and \#04/30 instruments. Each instrument was used with Xsmart Dentsply maillefer (Ballaigues, Switzerland) electrical motor at 600 revolutions per minute and $2 \mathrm{~N}$ torque. After the use of each instrument, root canals were irrigated with 2 $\mathrm{mL} 5 \% \mathrm{NaOCl}$ irrigation solution. Rotary files were changed after each 5 usage or when a deformation sign was observed.

\section{Group 3: Shaping of the root canals with PROTAPER.}

Working was started with the SX. S1 was used along the working length.

Shaping was completed along the working length using S2, F1, F2 and F3 instruments. Each instrument was used with Xsmart Dentsply maillefer (Ballaigues, Switzerland) electrical motor at 600 revolutions per minute and $2 \mathrm{~N}$ torque. After the use of each instrument, root canals were irrigated with $2 \mathrm{~mL} \mathrm{5 \%}$ $\mathrm{NaOCl}$ irrigation solution. Instruments were changed after each 5 usage or when a deformation sign was observed.

\section{CT imaging After Preparation}

Second images were taken under the same conditions in order to compare the models obtained before the preparation and those obtained after the preparation in terms of area and volume.

\section{Area and Volume Calculations Before and After Preparation}

Data obtained before and after preparation were transferred to the Mimics software. Appropriate voxels were similarly grouped in order to reconstruct 3D images based on the Hounsfield units (HU). For this purpose, a mask with defined $\mathrm{HU}$ values was created. Areas and volumes were calculated on the models obtained from the first and second images.
These measurements and calculations were made for all teeth.

\section{Statistical Analysis}

The descriptive analyses for the groups were calculated. The normality of the variation of the data was verified by the shapiro-wilk test $(\mathrm{P}=0.05)$. Data were subjected to One Way Anova $(\mathrm{P}=0.05)$. The data were analyzed using Statistical Package for the Social Sciences (SPSS Inc., Chicago, IL, USA) for Windows, version 15 software.

\section{Results}

Area changes that occurred during root canal preparation are shown in Figure 1, and volume changes in Figure 2.

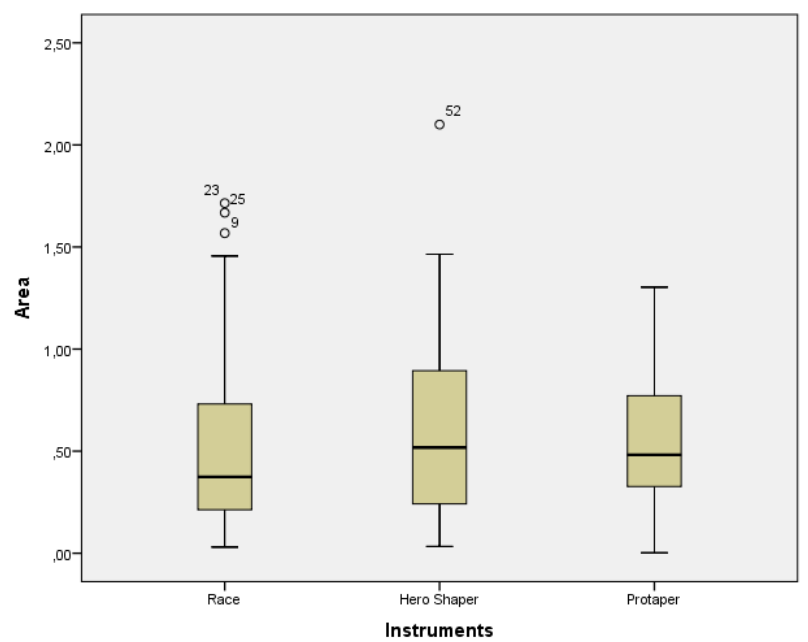

Figure 1. Mean values of changed area of groups $\left(\mathrm{mm}^{2}\right)$

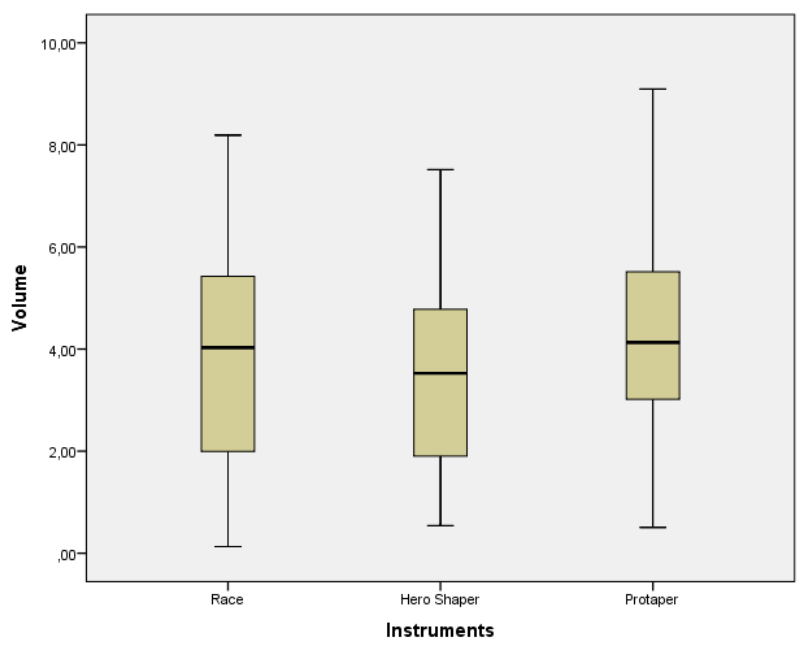

Figure 2. Mean values of changed volume of groups $\left(\mathrm{mm}^{3}\right)$ 
The images obtained before and after the preparation and were compared in all samples. Total area and volume differences were calculated. According to the results, no significant difference was found between the volumes on images in terms of the effectiveness of the instruments $(\mathrm{P}>0.47)$ (Table 1).

According to the results, no significant difference was found between the areas on images in terms of the effectiveness of the instruments $(\mathrm{P}>0.71)$ (Table $1)$.

Table 1. Mean and standard deviation of changed area/volume of groups

\begin{tabular}{lll}
\hline & Area $\left(\mathrm{mm}^{2}\right)$ & Volume $\left(\mathrm{mm}^{3}\right)$ \\
\hline Race & $0,57 \pm 0,51$ & $3,80 \pm 2,07$ \\
Hero Shaper & $0,61 \pm 0,46$ & $3,69 \pm 1,81$ \\
Protaper & $0,52 \pm 0,31$ & $4,25 \pm 1,84$ \\
& $\mathrm{P}=0,71$ & $\mathrm{P}=0,47$ \\
\hline
\end{tabular}

\section{Discussion}

According to results of the present study, there was no statistically significant difference among three different nickel titanium instrument systems in terms of the changed area and volume of root canals. Thus, the null hypothesis was accepted.

Removal of microorganisms from the root canal system is necessary for a successful endodontic treatment. Today, this is executed by chemical cleaning and shaping of the root canal system (Haapasalo et al. 2005; Paqué et al. 2009). Baker et al. 1975 reported that using a large amount of irrigation solution during root canal shaping will be beneficial. Mechanical preparation and irrigation should be combined in order to provide effective irrigation solutions delivery through the entire root canal system (Paqué et al. 2009). Shupping et al (Shuping et al. 2000). found that Ni-Ti instruments give the best effect when combined with irrigation solution. Although preparing to the root canals with large-taper instruments and effectively removing debris with preserving apical foramen cause a better irrigation, it is controversial topic that to which size of the root canals should be prepared (Albrecht et al. 2004). Since the living microorganisms can penetrate to the dentinal tubules, maintaining their life during root canal treatment, clinical importance of the shaped surface concept gains a different meaning (Peters et al. 2002). Therefore, shaping completed with larger apical numbers in which microorganisms can be mechanically removed and disinfection can be optimally applied are recommended (Dalton et al. 1998). In a declaration by the European Endodontic Society, it is reported that the preparation should cover the entire periphery of the canal in order to confirm complete cleaning and shaping of a canal (Undergraduate curriculum guidelines for endodontology. European Society of Endodontology 1992).

Many methods have been used to evaluate endodontic instruments for a few decades. These methods include plastic models' method, serial sections method, histological sections method, scanning electron microscope method and radiologic methods (Southard et al. 1987; Mizrahi et al. 1975; Bramante et al. 1987). Although destructive methods are easy, understandable and inexpensive, disadvantages such as substance loss occurring along the root canal due to fragmentation of the samples, difficulty in preparation between the portions, and errors during data transfer have caused the development of nondestructive methods. Imaging with CT has eliminated these disadvantages and also provided the opportunity of examining the samples with all aspects. However due to section thickness is not enough detailed images cannot be obtained, from small areas such as the apical region of the teeth. Microcomputed tomography (MCT) has been developed for this purpose. Although MTC provides very fine details and can be used successfully even in very small areas, it has some disadvantages such as requiring technical skills, expensive and difficult to access (Gluskin et al. 2001). Considering all these factors, in this study we used computed tomography.

In their study with MTC, Ikram et al. 2009 calculated volume changes occurring in the tooth during cleaning of decays, preparing the access cavity, root canal preparation with Protaper, preparation required for insertion of fiber post, and preparation required for insertion of cast post in 12 extracted upper premolars. They reported that volume changes occurred during removal of the decay by $8.3 \%$, preparing the access cavity by $4.4 \%$, root canal preparation by $1 \%$, fiber post preparation by $1.4 \%$, and cast post preparation by $4.1 \%$. In that study, the amount of removed dentin was calculated according to the tooth volume. The amount of dentin removed during root canal preparation was reported as $1 \%$. MCT gives more precise outcomes because of taking thinner sections during imaging. In this study, the total volume rate changed in the two canals of the upper premolars was given. We found the amount of removed dentin during root canal preparation as $0.5 \%$. The difference between the two results can be attributed to the type of the teeth used and MCT used for imaging.

In a study by Ozgur Uyanik et al. (2006) using CT, area and volume changes occurring during shaping of the mesial roots of the lower first molars were 
compared among three different instruments. Fourteen horizontal sections taken from the teeth were transferred to the 3D Doctor software, 3D model of the teeth was obtained, and area and volume changes were calculated on the $3 \mathrm{D}$ model. It was found that Hero Shaper, Protaper and Race removed a volume of $2.08 \pm 0.45,2.77 \pm 028$ and $2.40 \pm 1.53$ $\mathrm{mm} 3$, respectively. The authors demonstrated that Protaper removed a statistically significantly higher amount of dentin, while no significant difference was found between Race and Hero Shaper. No statistically significant difference found between the groups in terms of area change. In that study, calculations were made by obtaining a 3D model from $2 \mathrm{D}$ images of 1 $\mathrm{mm}$ thickness taken from the mesial roots of the lower molars. In our study, calculations were made by obtaining the model from 3D images of $0.5 \mathrm{~mm}$ thickness taken from the roots of the upper molars. Variation in selected teeth and section thicknesses might cause different numerical results between the studies. However, despite the differences in numerical values, the results are in parallel with our results in terms of the effectiveness of the instruments.

Mahran and AboEl-Fotouh 2008 took 14 horizontal sections from 45 mesio-buccal canals of the upper first molars using CT. They divided the teeth into three groups. They made preparation with Protaper in Group I, Hero Shaper in Group II and Gates glidden and Flex R hand file in Group III. The amount of removed dentin was calculated with Syngo CT software VB20. The authors stated that Protaper removed the statistically highest amount of dentin (1.6 mm3), while Group III removed the lowest amount $(0.93 \mathrm{~mm} 3)$. The difference of the study by Mahran and AboEl-Fotouh 2008 and by Ozgur Uyanik et al. (2006) was using of the upper molars instead of the lower molars. In these studies, 3D model was obtained from 2D images of $1 \mathrm{~mm}$ thickness. The results reported in that study different from the study by Ozgur Uyanik et al. (2006) might be attributed to the teeth used. The difference between our results and the results of these two studies might be resulted from obtaining the model from 3D images of $0.5 \mathrm{~mm}$ thickness. Although numerical values of the results were different, results of all three studies are consistent when effectiveness of the instruments was evaluated.

In their study, Loizides et al. (2007) compared the effectiveness of Hero group (endo flare, Hero Shaper, Hero apical) and Protaper on the mesial roots of the lower molars using MCT. They examined area changes in the sections taken at 2, 4, 6 and $8 \mathrm{~mm}$ from the apical. It was reported that Protaper changed more area than Hero group at $2 \mathrm{~mm}$, while Hero group changed more areas than Protaper at the other three levels. The authors found significant differences between the groups. In that study, area changes at different levels were studied, and it was found that the Hero group changed areas at more levels than Protaper. Different results from our study might be caused by the methods used.

\section{Conclusion}

Within the limits of this study, rotary instrument systems used during shaping of the root canals showed similar effects in terms of area and volume changes in the root canals.

Acknowledgments: This paper is taken from my thesis "Comparative Evaluation of Three NickelTitanium Instrumentation Systems in Human Teeth Using Computed Tomography" done in 2010 at Atatürk University.

Ethics Committee Approval: The Ethics Committee of graduate school of health sciences of Atatürk University, Erzurum, Turkey, approved (2010).

Peer-review: Externally peer-reviewed.

Author Contributions: Concept- F.C., A.S.E; Design- F.C; Materials- F.C; Data Collection and/or Processing- F.C; Literature Review- F.C, A.S.E; Writing- F.C.; Critical Review- F.C., A.S.E

Conflict of Interest: No conflict of interest was declared by the authors.

Financial Disclosure: The authors declared that this study hasn't received no financial support.

\section{References}

Albrecht Lynn J, Baumgartner JC, Marshall J. Evaluation of apical debris removal using various sizes and tapers of ProFile GT files. In Journal of endodontics 2004;30 (6): 425-428.

Baker NA, Eleazer PD, Averbach RE, Seltzer S. Scanning electron microscopic study of the efficacy of various irrigating solutions. In Journal of endodontics (1975) 1 (4):127-135.

Bramante CM, Berbert A, Borges RP. A methodology for evaluation of root canal instrumentation. Journal of endodontics (1987) 13 (5):243-245.

Dalton BC, Ørstavik D, Phillips C, Pettiette M, Trope M. Bacterial reduction with nickel-titanium rotary instrumentation. Journal of endodontics (1998) 24 (11):763-767. 
Gluskin AH, Brown DC, Buchanan LS. A reconstructed computerized tomographic comparison of $\mathrm{Ni}-\mathrm{Ti}$ rotary GT files versus traditional instruments in canals shaped by novice operators. International endodontic journal (2001) 34 (6):476-484.

Haapasalo M, Endal U, Zandi H, Coil JM. Eradication of endodontic infection by instrumentation and irrigation solutions. Endodontic Topics 2005;10 (1):77-102.

Ikram OH, Patel S, Sauro S, Mannocci F. Microcomputed tomography of tooth tissue volume changes following endodontic procedures and post space preparation. International endodontic journal 2009;42 (12):1071-1076.

Loizides AL, Kakavetsos VD, Tzanetakis GN, Kontakiotis EG, Eliades G. A comparative study of the effects of two nickel-titanium preparation techniques on root canal geometry assessed by microcomputed tomography. Journal of endodontics 2007;33 (12):1455-1459.

Mahran AH, AboEl-Fotouh MM. Comparison of effects of ProTaper, HeroShaper, and Gates Glidden Burs on cervical dentin thickness and root canal volume by using multislice computed tomography. Journal of endodontics 2008;34(10):1219-1222.

Mizrahi SI, Tucker JW.; Seltzer S. A scanning electron microscopic study of the efficacy of various endodontic instruments. Journal of endodontics 1975;1 (10):324-333.

Ozgur Uyanik M, Cehreli ZC, Ozgen MB, Tasman DF. Comparative evaluation of three nickeltitanium instrumentation systems in human teeth using computed tomography. Journal of endodontics 2006;32 (7):668-671.

Paqué F, Ganahl D, Peters OA. Effects of root canal preparation on apical geometry assessed by microcomputed tomography. Journal of endodontics 2009;35 (7):1056-1059.

Peters LB, Van Winkelhoff AJ, Buijs JF, Wesselink PR. Effects of instrumentation, irrigation and dressing with calcium hydroxide on infection in pulpless teeth with periapical bone lesions. International endodontic journal 2002;35 (1):1321.

Schneider SW. A comparison of canal preparations in straight and curved root canals. In Oral Surgery, Oral Medicine, Oral Pathology 1971;32 (2):271275.
Shuping GB, Orstavik D, Sigurdsson A, Trope M. Reduction of intracanal bacteria using nickeltitanium rotary instrumentation and various medications. Journal of endodontics 2000;26 (12):751-755.

Southard DW, Oswald RJ, Natkin E. Instrumentation of curved molar root canals with the roane technique. Journal of endodontics 1987;13(10):479-489.

Undergraduate curriculum guidelines for endodontology. European Society of Endodontology (1992). International endodontic journal (1992). 25 (3):169-172. 